\title{
Guideline-Oriented Therapy of Lower Extremity Peripheral Artery Disease (PAD) - Current Data and Perspectives
}

\section{Leitliniengerechte Therapie der PAVK - Aktuelle Studienlage und Ausblick}

Authors

Jonas Kersting ${ }^{1}$, Lars Kamper ${ }^{1}$, Marco Das ${ }^{2}$, Patrick Haage ${ }^{1}$

Affiliations

1 Radiology, Helios University Hospital Wuppertal, University Witten/Herdecke, Wuppertal, Germany

2 Radiology, HELIOS Klinikum Duisburg, Germany

Key words

aorta, blood vessels, vascular, angiography, angioplasty, arteriosclerosis

received 22.03.2018

accepted 01.08.2018

Bibliography

DOI https://doi.org/10.1055/a-0690-9365

Published online: 21.1.2019

Fortschr Röntgenstr 2019; 191: 311-322

(c) Georg Thieme Verlag KG, Stuttgart · New York

ISSN 1438-9029

Correspondence

Dr. Jonas Kersting

Klinik für diagnostische und interventionelle Radiologie,

HELIOS Universitätsklinikum Wuppertal, Heusnerstraße 40,

42283 Wuppertal, Germany

Tel.: ++49/2 02/8962087

jonas.kersting@rub.de

\section{ABSTRACT}

Background Because of the demographic change, lower extremity peripheral artery disease (PAD) is becoming increasingly relevant with respect to health economics. PAD patients often suffer from multiple diseases. Consequently, therapy is commonly complex and requires an interdisciplinary approach. Because of rapid technical developments, interventional endovascular therapy regimens play an increasingly important role.

Method Review and literature search on the basis of the current German S3 guidelines on the therapy of PAD as well as international guidelines. In terms of state-of-the-art therapies, relevant current studies were considered.

Results Knowledge of existing guidelines and recommendations as well as new therapeutic approaches is essential for the adequate therapy of PAD patients. A close cooperation between the interventional radiologist and the vascular surgeon is the key to success. In addition to established conservative approaches and invasive bypass surgery, the endovascular approach has been a mainstay in the TASC A and B environment for years. It has recently shown promising results in advanced PAD conditions, such as TASC $C$ and D. An endovascular-first strategy is defined in most guidelines.

Conclusion A primarily endovascular-first strategy has become the standard in the majority of even complex lesions of the lower extremity arterial system. Regarding the crural segment, a decrease in mortality compared to bypass surgery has been demonstrated. Further evidence can be expected from ongoing randomized multicenter trials.

Key Points:

- Adequate diagnostic examination is essential for the classification and strategy of therapy in PAD

- Therapeutic decisions are ideally made in an interdisciplinary conference

- Interventional therapy of intermittent claudication after exhaustion of conservative and medicamentous therapy

- Endovascular-first approach in supra- and infrainguinal lesions

- Additional evidence expected from future randomized trials

\section{Citation Format}

- Kersting J, Kamper L, Das M et al. Guideline-Oriented Therapy of Lower Extremity Peripheral Artery Disease (PAD) - Current Data and Perspectives. Fortschr Röntgenstr 2019; 191: 311-322

\section{ZUSAMMENFASSUNG}

Hintergrund Die periphere arterielle Verschlusskrankheit (PAVK) hat aufgrund des demografischen Wandels eine zunehmende gesundheitsökonomische Relevanz. PAVK-Patienten sind häufig mehrfach vorerkrankt und dementsprechend komplex und interdisziplinär zu behandeln. Der endovaskulär-interventionellen Therapie fällt dank rascher technischer Entwicklungen eine immer zentralere Rolle zu.

Methode Allgemeines Review mit Literaturrecherche, ausgehend von der aktuellen deutschen S3-Leitlinie zur Therapie der PAVK sowie aktuellen internationalen Leitlinien. Im Hinblick auf moderne Therapieverfahren fand die aktuelle Studienlage Berücksichtigung. 
Ergebnisse Die Kenntnis aktueller Leitlinien und Handlungsempfehlungen sowie neuer therapeutischer Tendenzen und Ansätze ist essenziell zur suffizienten Behandlung von PAVKPatienten. Zudem ist eine enge Zusammenarbeit zwischen interventioneller Radiologie und Gefäßchirurgie der Schlüssel zum Erfolg. Neben konservativen Ansätzen und den BypassOP-Verfahren haben die endovaskulären Ansätze stark an Bedeutung gewonnen. Diese sind in den PAVK-Stadien TASC $A$ und $B$ seit vielen Jahren Methode der Wahl und zeigen nunmehr vielversprechende Ergebnisse in der Behandlung von diffizilen TASC-C- und -D-Konstellationen. Eine primär endovaskuläre Strategie ist in einer Vielzahl der Fälle leitliniengerecht.

Schlussfolgerung Die primär endovaskuläre Vorgehensweise ist mittlerweile bei der Mehrzahl auch komplexer Läsionen der Becken-Bein-Achse zum Standard geworden. Der endovaskuläre Ansatz zeigt läsionsbezogen gut belegte Vorteile gegenüber der Bypass-Chirurgie, so zum Beispiel im Unterschenkelsegment eine Senkung der Mortalität. Weitere Evidenz wird zukünftig durch mehrere großangelegte randomisierte Multicenterstudien erwartet.

\section{Introduction/definition}

The term peripheral artery disease (PAD) refers to a restriction of the blood flow through the arteries or aorta supplying the extremities. This can be partial (stenosis) or complete (occlusion) [1].

Due to the increasingly older population and the growing number of patients with diabetes, the incidence and prevalence of PAD are increasing [1]. In 2009, PAD was responsible for $3 \%$ of all hospitalizations. In particular, there has been an increase in stage IV of the Fontaine classification [2]. One study expects an increase in the number of vascular medicine cases by 2020 of more than $40 \%[1]$.

In Germany, the prevalence of PAD across all age classes is $3-10 \%$ [3]. There is a prevalence of $20 \%$ in a 70 -year-old German patient population [1].

\section{Diagnosis}

After recording of the patient history and completion of the clinical examination, the ankle-brachial index (ABI) is a readily available and cost-effective diagnostic method [4]. An $A B I$ value $<0.9$ is pathological and indicative of PAD. The sensitivity for the presence of stenosis of at least $50 \%$ is almost $95 \%$ at rest with a specificity of almost $100 \%$ [1]. False-negative values can be seen in the case of highly calcified vessels.

Color-coded duplex sonography is highly available, cost-effective and noninvasive. Using color-coded duplex sonography, experienced examiners achieve a sensitivity of $88 \%$ and a specificity of $96 \%$ in PAD diagnosis [5]. The high time requirement is a disadvantage.

If a significant finding is not acquired in symptom-oriented treatment planning so that treatment cannot be initiated, the addition of CT angiography (CTA) or contrast-enhanced MR angiography (CE-MRA) is recommended [1].

CTA of the pelvis-leg region is a highly available, examinerindependent, noninvasive method for the supplementary diagnosis of PAD. According to multiple studies, aortoiliac stenosis of at least $50 \%$ is detected with a median sensitivity of $91 \%$ and a specificity of $91 \%[1,5]$. However, CTA has limited diagnostic significance in highly calcified vessels with a small diameter. An iodine-based contrast agent is needed for contrast enhancement of vessels. Limited applicability in patients with renal insufficiency is the subject of current studies and does not seem to be absolutely necessary based on current knowledge [6].

CE-MRA is also a noninvasive, examiner-independent diagnostic method that allows high-resolution three-dimensional reconstruction [5]. With a sensitivity of $95 \%$ averaged over multiple studies and a median specificity of $97 \%$, it has the highest diagnostic value among noninvasive diagnostic methods [1]. However, due to insufficient data, it is not recommended as a firstline diagnostic method for infrapopliteal stenosis in patients with diabetes [7] ( $\triangleright$ Table 1).

In therapy-oriented diagnosis, particularly with respect to detail resolution and clarity, DSA is still the gold standard $[1,8]$. In addition to diagnosis with the possibility of simultaneous intervention (DSA with readiness for PTA), visualization of a possible connecting vessel prior to planned bypass surgery can be crucial [1]. The complication rate of DSA is between $0.5 \%$ and $1 \%$ depending on comorbidities and risk factors. This complication affects patient management in $0.7 \%$ of cases and has a low mortality of $0.16 \%[1,9]$.

\section{Classification and treatment approach}

Almost $75 \%$ of all PAD patients do not have any early symptoms [10]. Warning signals and a worsening of symptoms are often ignored and misinterpreted. Due to this lack of knowledge and an underestimation of the consequences of PAD, compliance with conservative therapy in terms of walking training and the taking of medication is very low [1]. Moreover, walking training is not possible for many PAD patients due to comorbidities. Structured arm training can be considered here. Successful use shows that the physiological processes involved in improving PAD are not fully understood [11]. With respect to patient compliance and the consequences of lesions, conservative long-term therapy does not seem promising [1].

PAD must be treated on an interdisciplinary basis with inclusion of vascular risk factors and comorbidities, particularly coronary heart disease and cerebrovascular disease [1]. Endovascular as well as surgical treatments are a central component of PAD treatment. These therapies are complementary and should be offered at centers as hybrid procedures. These hybrid procedures are combinations of vascular surgery with exposure of an artery and interventional radiology therapy via the surgically created access. 
- Table 1 Sensitivity and specificity of different imaging modalities in the diagnosis of symptomatic PAD for stenosis $>50 \%$ and occlusion in the lower extremity.

\begin{tabular}{|l|c|c|c|}
\hline & $\begin{array}{l}\text { color-coded du- } \\
\text { plex sonography }\end{array}$ & CTA & CE-MRA \\
\hline number of studies & 7 & 6 & 7 \\
\hline median sensitivity in \% & 88 & 91 & 95 \\
\hline median specificity in \% & 96 & 91 & 97 \\
\hline
\end{tabular}

Treatment decisions should be made in an interdisciplinary manner on the basis of stage-oriented consideration of risks and benefits [1].

PAD can be clinically classified on the basis of symptoms according to Fontaine and Rutherford with the Fontaine classification being more common in Europe ( $>$ Table 2) [1]. This clinical classification is an obligatory part of interdisciplinary treatment decisions.

Patients are categorized based on symptomatic stages according to Fontaine as intermittent claudication (IC) corresponding to stage II, and critical limb ischemia (CLI) corresponding to stages III and IV.

The indication for interventional therapy should be determined using the Fontaine and/or Rutherford classification based on clinical stages. However, additional parameters should be taken into consideration, i. e., the location, morphology, and complexity of the vascular lesions because these are also relevant for treatment decisions [1].

Moreover, comorbidities and the patient's individual treatment wishes play a role in the treatment approach. Particularly patients in the critical limb ischemia (CLI) group are often chronically ill with multiple comorbidities [9].

To date, the classification of the Trans Atlantic Inter-Society Consensus (TASC or TASC II) has been used for the morphological classification of PAD. Lesions are summarized in the TASC classification and assigned a grade of A to D. There are TASC II classifications for the regions in the aortoiliac, femoropopliteal, and cruropedal segment. Due to the rapid technical development of endovascular treatment options, TASC II classification alone no longer seems sufficient for determining a therapeutic approach since it is now possible to treat TASC D lesions with endovascular intervention $[1,12]$.

A newer, more complex procedure is needed to decide between open surgery and endovascular intervention.

The current S3 guidelines for the diagnosis, therapy, and follow-up of PAD provide constellations of angiomorphologic criteria which primarily contraindicate endovascular therapy [1]. These include, for example, extensive occlusions, occlusions without connecting segments and occlusions of the common femoral artery. This assessment is in agreement with that of the American guidelines [13].

The specified angiomorphologic criteria result in the following constellations of angiomorphologic findings to be primarily treat- ed with vascular surgery. The list includes all levels of the vasculature of the pelvis-leg region [1]:

- Subrenal aortic occlusion with occlusion of the bilateral common iliac artery.

- Occlusion of the common femoral artery

- Occlusions of the external iliac artery or the superficial femoral artery that reach the common femoral artery

- Occlusions of the trifurcation with extensive occlusion of the superficial femoral artery and the popliteal artery

- Extensive occlusions of the popliteal artery, the trifurcation, and all US arteries with one or more well preserved distal crural or pedal connecting segments

There is consensus that the asymptomatic stage I of PAD should not be treated on a prophylactic basis [1]. An exception in individual cases is prophylactic treatment of patients with polyneuropathy, including diabetic polyneuropathy. In the case of a risk of the development of foot lesions in these patients, prophylactic treatment of asymptomatic but hemodynamically relevant stenoses can be useful [14]

For patients with CLI or a diabetic foot syndrome, a new classification for risk stratification of a leg amputation and for determining the prognosis of the outcome after revascularization was proposed and is highly accepted [15]. This classification include points for the factors "wound", "ischemia", and "foot infection", collectively referred to as "WIFi" [15]

However, the goal should always be revascularization $[16,17]$.

\section{Treatment according to stages and segments}

\section{Intermittent claudication (IC)}

IC is present beginning in stage II according to the Fontaine classification. The goal of treatment should be to improve walking distance, symptoms, and quality of life.

Comprehensive conservative or supportive therapy includes regular and monitored walking training. Studies have shown that there is no difference in outcome between surgical treatment and structured walking training [18]. A significantly improved walking distance after endoluminal PTA compared to structured walking training was able to be shown in the MIMIC study [19]. However, additional evidence is lacking here. Nonetheless, initial PTA with subsequent structured vascular training yields the greatest success [19] ( $\triangleright$ Fig. 1). Treatment with medication alone has limited therapeutic success [20]. Statins seem to be most promising here.

\section{Aortoiliac segment}

Aortoiliac stenoses and occlusions are a common cause of IC. If the stenosis/occlusion is less than $5 \mathrm{~cm}$, an endovascular strategy with a patency rate of $>90 \%$ after 5 years and a low complication rate is indicated [21]. Also because conservative therapy has little chance of success in the region of the pelvic arteries, the guidelines recommend a primary endovascular treatment approach [ 1 , 22 ]. In the case of iliofemoral lesions, particularly with involve- 
- Table 2 Fontaine classification and Rutherford classification.

\begin{tabular}{|l|l|l|l|l|}
\hline Fontaine & & Rutherford & & clinical picture \\
\hline stage & clinical picture & grade & category & asymptomatic \\
\hline I & asymptomatic & 0 & 0 & mild intermittent claudication \\
\hline Ila & walking distance $>200 \mathrm{~m}$ & I & 1 & moderate intermittent claudication \\
\hline IIb & walking distance $<200 \mathrm{~m}$ & I & 2 & severe intermittent claudication \\
\hline & & I & 3 & ischemic rest pain \\
\hline III & ischemic rest pain & II & 4 & small area of necrosis \\
\hline IV & ulcer, gangrene & III & 5 & large area of necrosis \\
\hline
\end{tabular}

ment of the common femoral artery, hybrid methods should be considered. If the stenosis extends across the aortic bifurcation into the infrarenal aorta, endovascular remodeling of the aortic bifurcation using covered stents can be considered. A small study with 103 patients was able to show good primary patency rates after 1 and 2 years of $87 \%$ and $82 \%$, respectively [23]. However, open surgical reconstruction of the aortic bifurcation is the standard in the guidelines provided that the health of the patient is sufficient and the surgical risk is reasonable [1]. Primary interventional radiology treatment worsens the prognosis for subsequent vascular surgery to a proven degree.

\section{Femoropopliteal segment}

Nitinol stents have no significant advantage over PTA in the intermediate follow-up with respect to patency rate and need for reintervention for the femoropopliteal segment in small lesions with a length of $<5 \mathrm{~cm}$ [24]. However, studies show that a self-expanding nitinol stent should be used to treat stenoses with a length of $100 \mathrm{~mm}$ or greater [1]. 3-year patency rates of $42-76 \%$ have been seen with a significant advantage for patients primarily treated with a self-expanding nitinol stent compared to primary PTA with bail-out stenting [25]. The current German S3 guidelines categorize this correlation as evidence class 2 [1].

Balloons coated with paclitaxel (DEBs) showed a significant advantage with respect to reintervention and restenosis rates compared to conventional PTA with uncoated balloon catheters in a meta-analysis in the intermediate follow-up [26]. The advantage of DEBs is the minimization of intimal hyperplasia. If these advantages are important for patient management, the use of DEBs can be considered according to the current S3 guidelines [1].

Stenoses/occlusions with a length of up to $25 \mathrm{~cm}$ should be treated primarily in an endovascular manner. An endovascular approach is also possible in the case of a length of over $25 \mathrm{~cm}$, but bypass surgery with vein bypass has better long-term patency rates and lower reintervention rates [17].

A special drug eluting stent (DES) has better 5-year patency rates in the femoral segment than PTA and self-expanding stents (72.4\% vs. $53 \%$ ) [27]. However, large randomized studies on this subject are lacking. A French study and a British study showed that a primary DES can have an economic advantage due to the lower reintervention rates compared to PTA and self-expanding stents [28, 29].

However, the consensus recommendation of the German S3 guidelines is that the clinical value of drug-coated stent implants currently cannot be sufficiently evaluated [1].

One possible way to improve patency and restenosis rates is lesion preparation. Individual studies were able to show positive approaches for lesion preparation with preceding atherectomy or with the use of a scoring balloon [30, 31]. However, there are only a few randomized studies on this topic so that the value cannot be definitively determined.

\section{Infrapopliteal segment}

Insufficient data with long-term results with respect to the infrapopliteal segment is available [1]. This may be due to the fact that $43 \%$ of IC patients have a sufficient 3-vessel blood supply to the lower leg as shown by the German PSI study [9].

An upstream stenosis/occlusion should undergo primary treatment. Infrapopliteal treatment in the IC stage is currently not recommended by all guidelines [1, 22].

\section{Critical limb ischemia (CLI)}

CLI includes stages III and IV of the Fontaine classification. The treatment target for CLI is completely different than in IC and primarily targets the preservation of the extremity, improvement of the quality of life, and a reduction of the mortality rate [1]. CLI has a mortality rate of $25 \%$ within 12 months and an amputation rate of approximately $50 \%$ among untreated patients [1]. According to the general opinion in the literature, the goal should always be revascularization [16, 32, 33]. Heparin and a corresponding pain medication are part of the basic treatment of CLI. The decision as to whether a patient is suitable for revascularization should be made based on detailed imaging and the clinical picture using the WIFi classification (see above). A decision is then made between an endovascular and a surgical approach ( Fig. 2).

The number of endovascular revascularization procedures and the associated reinterventions in CLI is increasing significantly in 


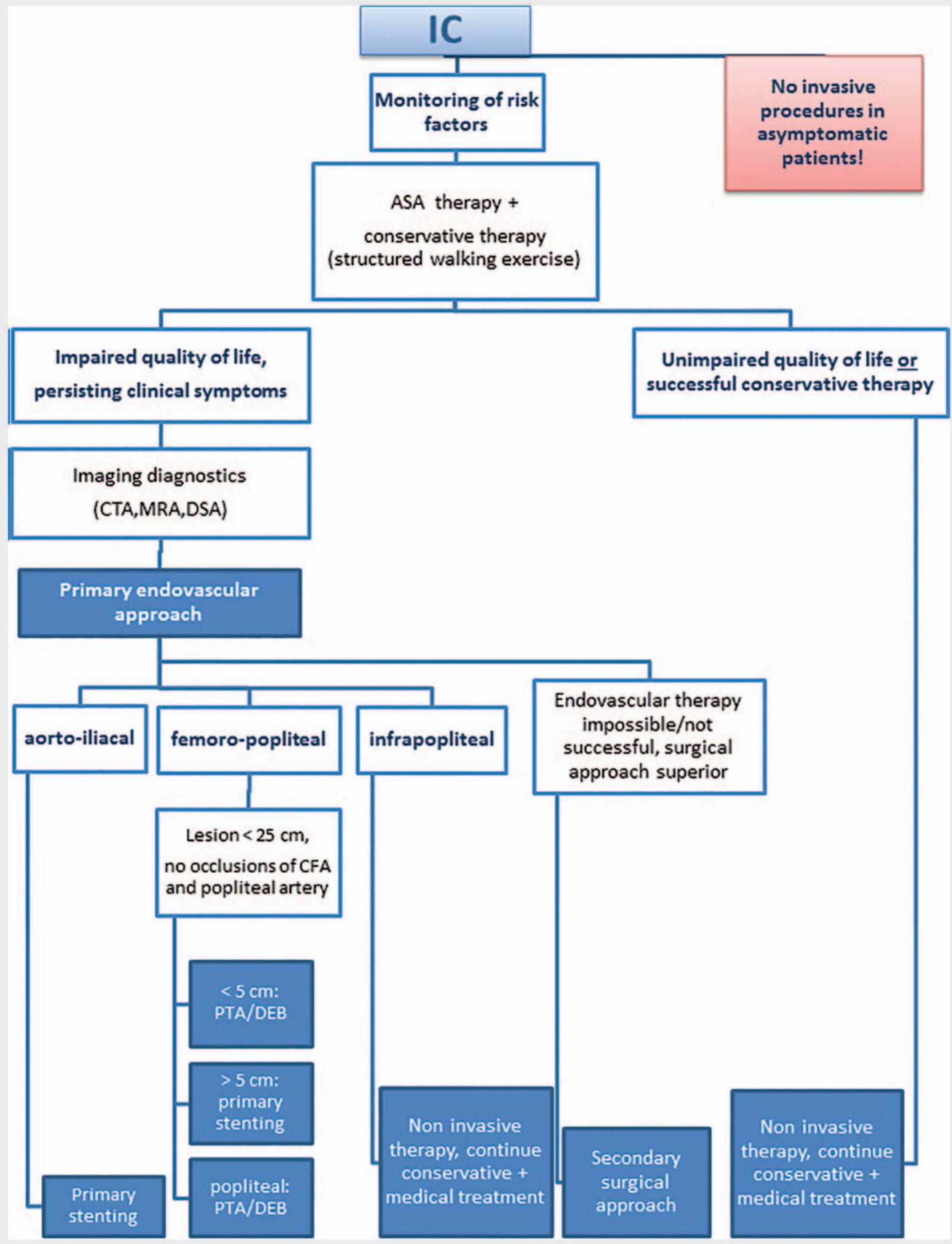

- Fig. 1 Treatment regime IC. 
the USA and Germany. At the same time, the number of bypass surgeries is decreasing [34].

\section{Aortoiliac segment}

In a review including 19 cohort studies, it was able to be shown in particular that the secondary long-term patency rates in complex aortoiliac lesions (TASC II C and D) after endovascular therapy is comparable to that of surgical bypass procedures [35]. The 1year patency rate in aortoiliac TASC C and D lesions is significantly higher in primary stenting (92\%) than in secondary/selective stenting (83\%) with both IC and CLI patients being included here [36]. A lower primary success rate and a higher complication rate can be expected in endovascular therapy of TASC D lesions compared to TASC A-C lesions. However, the long-term patency rate after 5 years ( $78 \%$ ) does not differ as shown by a Japanese follow-up study including 2600 interventions [37].

A prospective, non-randomized multicenter study was able to show primary 1-year patency rates after endovascular stenting of TASC C and D lesions of $91.3 \%$ and $90.2 \%$ [38]. This is also an indication for primary stent implantation. Therefore, this is also a consensus recommendation of the current German S3 guidelines for the treatment of PAD [1]. A promising 4-year patency rate of $87 \%$ could be shown in a retrospective multicenter study for a self-expanding nitinol stent [39].

Covered stent grafts showed promising primary patency rates in the treatment of complex TASC D lesions involving the aortic bifurcation [40]. However, there is a lack of sufficiently large comparison studies and a long-term follow-up for a final assessment. Moreover, the high cost of covered stent grafts should be noted here.

\section{Femoropopliteal segment}

The femoral or popliteal segment is rarely affected on an isolated basis in CLI. In $40 \%$ of cases, a proximal lesion must be treated prior to femoral intervention. In femoropopliteal lesions with a length of $<5 \mathrm{~cm}$, the current S3 guidelines recommend primary PTA for treating PAD. A clear advantage of primary stenting (nitinol stenting) with respect to patency rates and reintervention rates could not be shown here [1]. After an insufficient PTA result, bail-out stenting outside as well as on the level of the segments of motion can be considered [1].

As in the IC stage, the goal should be to avoid intimal hyperplasia and restenosis/reintervention. Therefore, the current $\mathrm{S3}$ guidelines recommend the use of DEBs [1]. This can also be relevant in the treatment of in-stent stenoses. In the case of highly calcified lesions, the use of DEBs with atherectomy systems or cutting balloons could have a theoretical advantage. However, there is currently insufficient data.

For lesions with a length of $5 \mathrm{~cm}$ or greater, the German S3 guidelines recommend primary stenting based on the clear advantages regarding restenosis rates and reintervention rates shown in the literature [1] ( $\triangleright$ Fig. 2). Also in this case single stenting should be given preference over overlapping stenting. Common complications of overlapping stenting include stent fractures and in-stent stenoses. As the largest, randomized comparison study, the BASIL study did not show a significant difference in mortality and amputation-free survival between endovascular PTA therapy and bypass surgery in the long-term follow-up of 5 years. However, patients from the bypass group who lived 2 years after randomization survived 7.3 months longer [41]. This resulted in the recommendation in the $\mathrm{S} 3$ guidelines to treat patients with a vascular occlusion with a length $>25 \mathrm{~cm}$, a low surgical risk, a good autologous vein and an expected survival of $>2$ years with bypass [1]. The current AHA/ACC guidelines define a primary endovascular approach regardless of the lesion length if the connected segments of motion are not affected [22].

A meta-analysis showed that the use of covered stent prostheses could have advantages with respect to the 1-year patency rate and stent fractures compared to covered stents, atherectomy and drug eluting stents (DESs). The authors see covered stents as a possible alternative, in particular in the treatment of long $(>15 \mathrm{~cm})$ or/and highly calcified lesions [42]. However, further comparative prospective multicenter studies are requested by the authors for confirmation.

No significant differences were seen between an ePTFE plastic bypass and a covered stent in femoral lesions with respect to primary long-term patency. After 48 months, a primary patency rate of $59 \%$ was seen in the stent graft group and $58 \%$ in the bypass group [43].

In the femoropopliteal segment, paclitaxel-coated stents (DESs) have promising primary 1-year and 2-year patency rates of $85 \%$ and $75 \%$, respectively, with a low reintervention rate of $13 \%$ [44]. Due to the lack of patient-relevant end points like walking distance, morbidity, mortality, quality of life and leg retention, a recommendation is not included in the current $\mathrm{S3}$ guidelines [1]. Moreover, most studies here are industry-sponsored.

The implantation of stents in segments of motion or segments with possible bypass anastomosis is not recommended but can be considered in the case of a risk of loss of a limb or in the CLI stage [1]. A typical complication after stent implantation in segments of motion is stent fracture which consequently leads to a higher rate of occlusion.

In 8 studies with patient numbers between 34 and 470, a specific woven stent has achieved promising primary patency rates between $78.9 \%$ and $87.7 \%$ in the treatment of lesions with a length between 78 and $240 \mathrm{~mm}$ [45]. Moreover, a successful popliteal application with primary 1-year patency rates between $68 \%$ and $81 \%$ could be shown in 4 of 8 studies. Stent fractures were not observed here [45]. The higher radial force that can be applied by woven stents is indicated as a possible cause. Woven nitinol stents are promising compared to classic open-cell or close-cell stent designs, particularly in segments of motion [45]. Without further patient-relevant end points, it is currently too early to make a general recommendation.

\section{Infrapopliteal segment}

Extensive infrapopliteal PAD is mainly only seen in diabetics. In most cases, proximal lesions often of the superficial femoral artery are seen in addition to lesions of the arteries of the lower leg. No significant difference with respect to amputation-free survival between primary endovascular treatment and open surgery could be shown in the prospective randomized BASIL study. More- 
over, retrospective cohort analyses could not show any significant difference with respect to patency rates and leg retention rates between the two procedures [1]. Nonetheless, endovascular treatment via PTA has high success rates in infrapopliteal stenoses as well as extensive occlusions in the CLI stage. Lower periprocedural morbidity and mortality compared to surgical alternatives were seen so that primary endovascular treatment is recommended in the German S3 guidelines [1].

In multiple studies, DEBs in the lower leg region showed promising results with respect to primary patency rates, reintervention rates, and secondary wound healing [1]. However, a large prospective controlled study was not able to confirm the advantage of DEBs with respect to reintervention rates. In fact, the study even showed a tendency toward a higher rate of major amputations in the DEB study arm and was discontinued [46]. Therefore, the value of the use of DEBs in infrapopliteal lesions cannot be definitively determined based on the currently available studies. This is in agreement with the recommendations of the German S3 guidelines regarding the treatment of PAD [1].

Superiority of primary stenting of the infrapopliteal vasculature in comparison to PTA could not be shown in multiple studies [1]. However, secondary stenting can be considered after PTA with a poor angiographic result [1].

DESs coated with paclitaxel or sirolimus have shown some promising results with respect to intermediate patency rates and reintervention rates. Additional studies particularly regarding the clinical end points limb retention and amputation-free survival are needed to be able to include a general recommendation in the guidelines [1] ( $\triangleright$ Fig. 2).

\section{Acute limb ischemia (ALI)}

A patient with suspicion of acute limb ischemia should be transferred as quickly as possible to an inpatient setting with sufficient diagnostic and therapeutic expertise, ideally a vascular center. The 6P rules (pain, pallor, pulselesness, paresthesia, poikilothermia, paralysis) can be used to assess whether acute ischemia is present. The main goal of ALI treatment should be quick reperfusion of the ischemic area.

Acute limb ischemia can be treated by endovascular intervention using catheter lysis or open surgery with a similar outcome. Fast availability and corresponding expertise regarding the treatment method are more decisive than the selection of the method ( $\triangleright$ Fig.3) even if multiple studies have shown that the mortality rate seems to be slightly higher in the case of surgical treatment [1]. For this reason, the endovascular method is often the treatment method of choice in ALI.

Three different tools are available for endovascular intervention:

- Catheter lysis via multipurpose or multiple sidehole infusion catheter

- Mechanical thrombectomy via aspiration catheter

- Mechanical thrombectomy via special thrombectomy catheter

The surgical approach primarily includes two different methods:

- Open surgical thrombectomy/arterial repair

- Surgical bypass
A modern concept including a combination of thrombectomy via aspiration catheter and catheter lysis yielded 6-month amputation rates of $<10 \%$ [1]. However, systemic lysis does not play a role in the treatment of ALI. The selection of a method should be based on the patient's symptoms and the duration and location of the occlusion. For an occlusion lasting $<14$ days, the best outcome is achieved with endovascular treatment [47].

Catheter lysis should be performed using urokinase, for example. The recommended treatment regime for urokinase is $240000 \mathrm{IU} / \mathrm{h}$ in the first 4 hours followed by $120000 \mathrm{IU} / \mathrm{h}$ for up to 48 hours. An initial bolus of $250000 \mathrm{IU}$ is possible. The technical success rate with complete resolution of the thrombus is $69-81 \%$ here [48]. Alternative thrombolytic drugs, e. g. alteplase, tenecteplase and reteplase, with corresponding treatment regimes are also available [1, 48].

Stage IV according to the Fontaine classification must often undergo primary treatment with removal of the dead tissue or even amputation.

A number of mechanical thrombectomy tools are currently being tested. Various thrombectomy approaches are being followed. These range from systems with helical rotating waves which aspirate the thrombus material via suction to systems which fragment and then aspirate thrombus material using the Bernoulli effect via an $\mathrm{NaCl}$ jet (rheolytic thrombectomy). Some of these methods show promise but are not yet mentioned in the current S3 guidelines. Additional significant and comparative studies are needed to be able to evaluate the value of these methods in the treatment of ALI.

\section{Periinterventional administration of medication}

Thrombocyte aggregation inhibition represents an important part of prophylactic medication-based treatment of PAD since PAD patients have increased thrombocyte activation. Arterial thromboses must be prevented and multilateral mortality must be decreased. In particular, patients with diabetes or chronic renal insufficiency have an increased postinterventional risk of restenosis [1].

Restenoses occur in three consecutive phases ( $\vee$ Table 3 ).

According to the current $\$ 3$ guidelines, pre-, peri-, and postinterventional treatment with aspirin salicylic acid (ASS) at a dose of $100 \mathrm{mg}$ per day is recommended for all PAD patients if not contraindicated. If tolerated, ASS therapy should be continued throughout the patient's entire life [1].

The administration of unfractionated heparin before and during intervention is standard in the treatment of IC, CLI, and ALI. The activated coagulation time should be extended to $>200$ seconds to prevent thromboses. In addition to its antithrombotic properties, unfractionated heparin also has antiproliferative effects [1]. The additional administration of low-molecular heparin resulted in significantly higher patency rates in the treatment of ALI [1].

Thrombocyte aggregation inhibition with both ASS and clopidogrel for infrainguinal use after PTA or stent implantation has currently not been sufficiently observed on a comparative basis. However, due to the good results in postinterventional therapy 


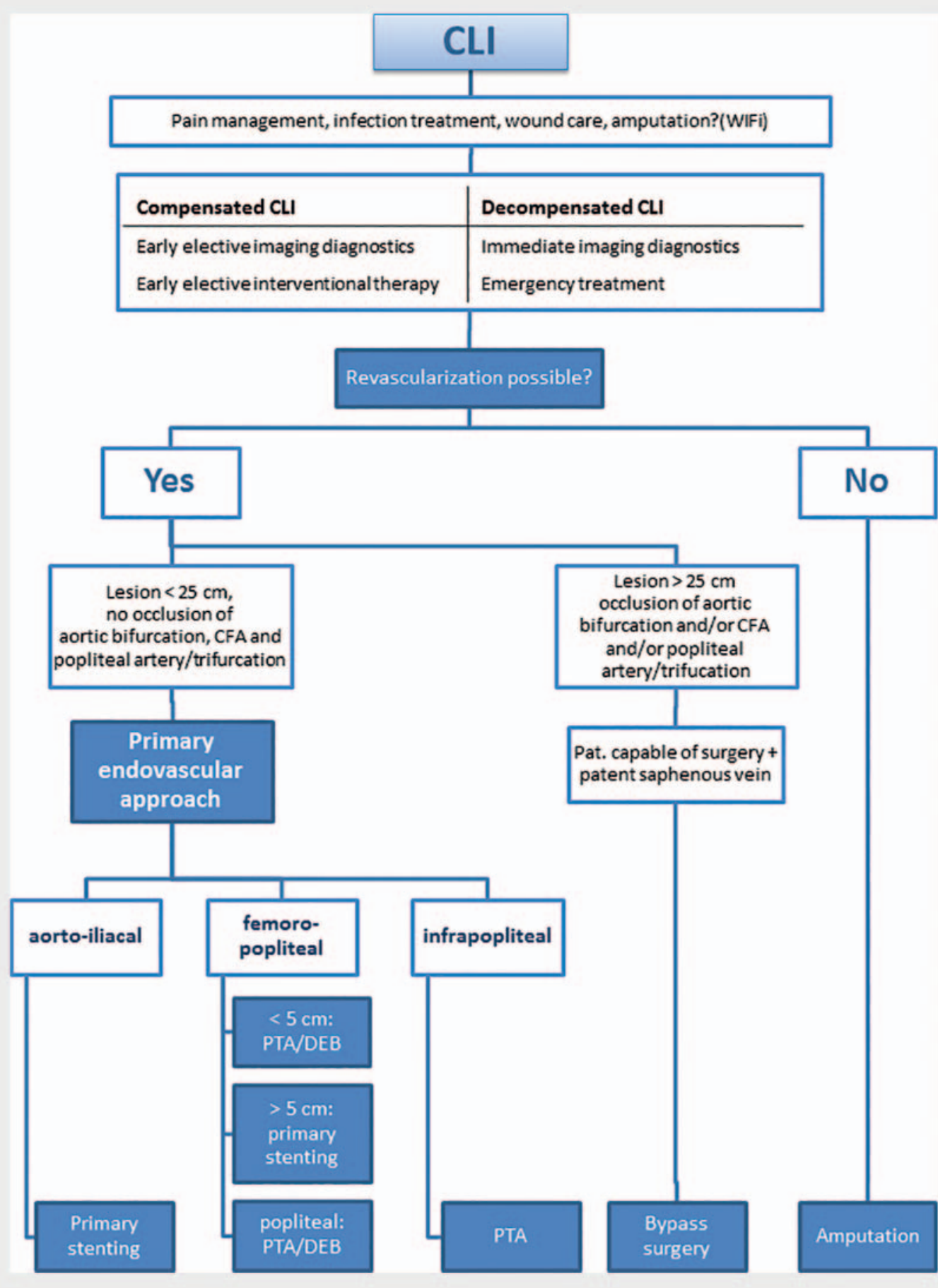

- Fig. 2 Treatment regime CLI.

after coronary stenting and the pathophysiology of early and intermediate stent thromboses, the $\mathrm{S} 3$ guidelines include a consensus recommendation. They recommend thrombocyte aggregating inhibition with both ASS and clopidogrel after infrainguinal stent placement. The usual dose is $75 \mathrm{mg}$ clopidogrel per day for a period of $6-8$ weeks. A loading dose is viewed with skepticism and a need has not yet been proven [1].
Oral anticoagulants (coumarin derivatives) should not be used after PTA due to the greater risk of bleeding. Alternatively, the current S3 guidelines reference treatment with thrombocyte function inhibitors [1].

Sufficient pain therapy should always be part of the treatment of CLI, particularly ALI. Patient-adapted, periinterventional pain treatment is also important in endovascular treatment [1]. 


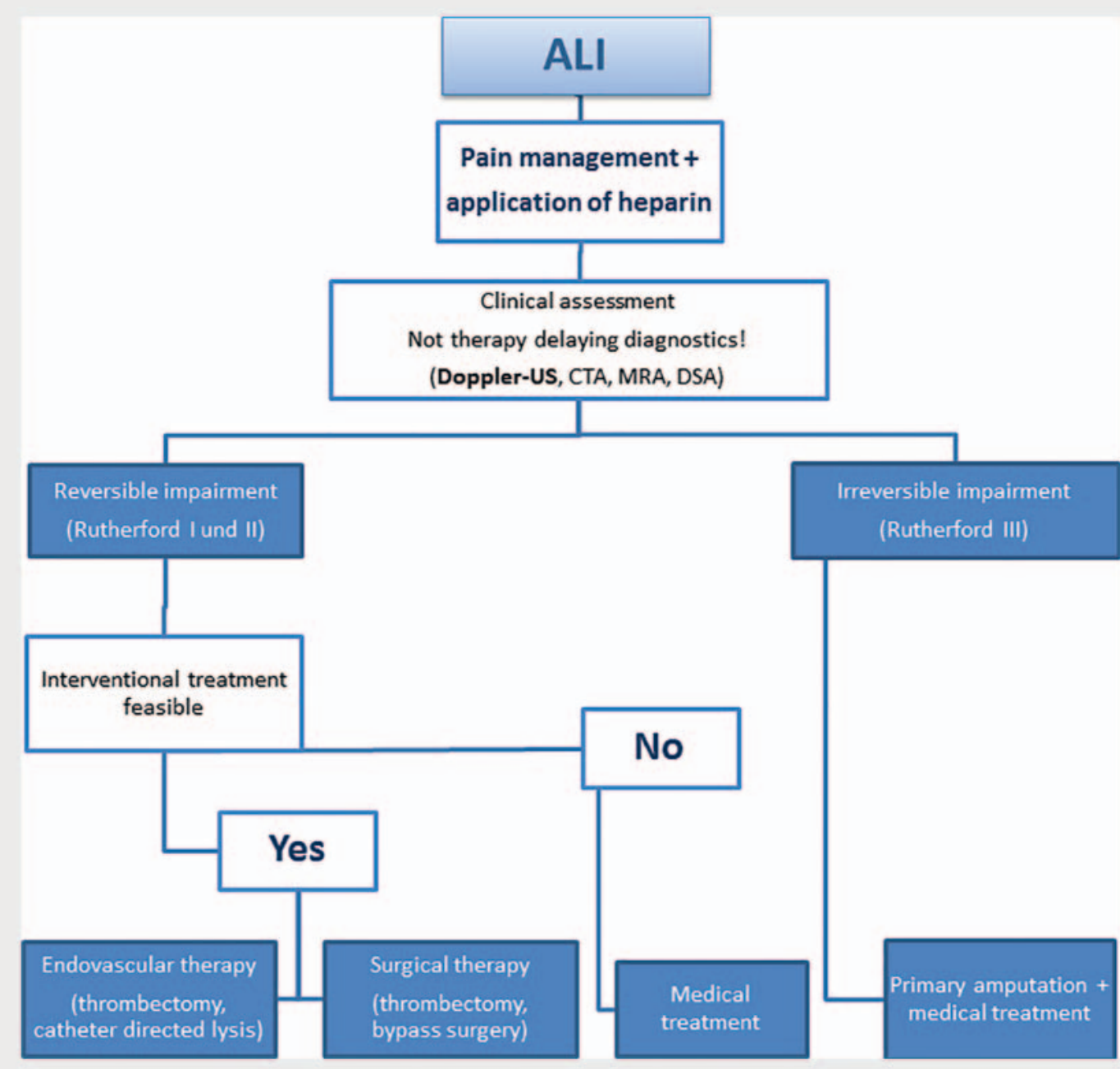

- Fig. 3 Treatment regime ALI [1, 9].

\section{Summary}

Appropriate diagnosis and treatment of PAD patients presents a challenge for the treating medical disciplines. As a result of the continually increasing number of affected patients and the growing number of concomitant diseases, the problem can only be addressed on an interdisciplinary basis. Patients with complex cases should visit interdisciplinary vascular centers. There are approximately 100 such centers in Germany. The goal should be guideline-compliant and evidence-based treatment. Vascular surgery, interventional radiology, and angiology work in close cooperation here. Cases and the corresponding diagnosis are to be discussed on an interdisciplinary basis to determine the proper treatment. In addition to other quality assurance modules, mortality and morbidity conferences are held at regular intervals to identify any problems.

Comprehensive diagnosis with determination of the location, length, and complexity of the occlusion process is particularly important. Moreover, treatment depends on the expertise of the physician, the available equipment and the patient's degree of suffering, particularly in the case of IC [1]. The Fontaine classifica-
- Table 3 Chronological sequence of restenosis/complications.

\begin{tabular}{|l|l|}
\hline $\begin{array}{l}\text { restenosis/ } \\
\text { time period }\end{array}$ & cause \\
\hline 24 hours p.i. & $\begin{array}{l}\text { elastic recoiling after PTA } \rightarrow \text { can be prevented by } \\
\text { stenting }\end{array}$ \\
\hline 2 weeks p.i. & thrombus formation \\
\hline 3 months p.i. & neointimal hyperplasia with restenosis \\
\hline
\end{tabular}

tion assists in clinical decision-making. Direct derivation of treatment from the TASC II classification is no longer recommended.

Endovascular treatment approaches are becoming increasingly important in all Fontaine stages and on every level of the vasculature of the pelvis and legs. This is due to the availability of more extensive data and the continuous progress of the intervention material. "Below-the-knee" interventions have been the standard for some time. In the CLI stage, PTA had a lower periprocedural 
morbidity and mortality rate compared to the surgical alternative. The use of DEBs in the femoropopliteal segment is currently recommended. To date, no significant advantage of the use of DEBs in the infrapopliteal segment has been able to be shown.

Endovascular intervention is the method of choice with respect to the ALI stage. Particularly in temporary occlusions, the endovascular approach is a treatment option with good results.

There is a need for additional, independent, comparative, randomized multicenter studies addressing the various endovascular technologies and vascular surgery with respect to IC and CLI. The focus of the outcome should not be the patency rate but rather patient-centered end points such as quality of life and amputation-free survival. Reintervention rates and mortality rates should also be taken into consideration. A conclusion regarding the costeffectiveness and cost efficiency of a particular method would also be desirable from a health economics standpoint.

\section{Conflict of Interest}

The authors declare that they have no conflict of interest.

\section{References}

[1] Lawall H, Huppert P, Zemmrich CS et al. S3-Leitlinie PAVK - Diagnostik, Therapie und Nachsorge der peripheren arteriellen Verschlusskrankheit. Vasa 2016; 45 (Suppl. 95): 1 - 100. doi:10.1024/0301-1526/a000579

[2] Malyar N, Furstenberg T, Wellmann J et al. Recent trends in morbidity and in-hospital outcomes of in-patients with peripheral arterial disease: a nationwide population-based analysis. Eur Heart J 2013; 34: 2706 2714. doi:eht288 [pii] 10.1093/eurheartj/eht288

[3] Diehm C, Schuster A, Allenberg JR et al. High prevalence of peripheral arterial disease and co-morbidity in 6880 primary care patients: crosssectional study. Atherosclerosis 2004; 172: $95-105$. doi:S00219150(03)00204-1 [pii]

[4] Krause D, Burghaus I, Thiem $U$ et al. The risk of peripheral artery disease in older adults - seven-year results of the getABI study. Vasa 2016; 45 : 403-410. doi:10.1024/0301-1526/a000556

[5] Collins R, Burch J, Cranny G et al. Duplex ultrasonography, magnetic resonance angiography, and computed tomography angiography for diagnosis and assessment of symptomatic, lower limb peripheral arterial disease: systematic review. BMJ 2007; 334: 1257. doi: bmj.39217.473275.55 [pii] 10.1136/bmj.39217.473275.55

[6] McDonald JS, McDonald RJ, Lieske JC et al. Risk of Acute Kidney Injury, Dialysis, and Mortality in Patients With Chronic Kidney Disease After Intravenous Contrast Material Exposure. Mayo Clin Proc 2015; 90: 1046 - 1053. doi:S0025-6196(15)00468-1 [pii] 10.1016/j. mayocp.2015.05.016

[7] Healy DA, Boyle EM, Clarke Moloney M et al. Contrast-enhanced magnetic resonance angiography in diabetic patients with infra-genicular peripheral arterial disease: systematic review. Int J Surg 2013; 11: 228 232. doi:S1743-9191(13)00032-0 [pii] 10.1016/j.ijsu.2013.02.001

[8] Owen AR, Roditi GH. Peripheral arterial disease: the evolving role of non-invasive imaging. Postgrad Med J 2011; 87: 189-198. doi: pgmj.2009.082040 [pii] 10.1136/pgmj.2009.082040

[9] Behrendt CA, Heidemann F, Haustein K et al. Percutaneous endovascular treatment of infrainguinal PAOD: Results of the PSI register study in 74 German vascular centers. Gefasschirurgie 2017; 22: 17-27. doi:10.1007/s00772-016-0202-2202 [pii]

[10] Alahdab F, Wang AT, Elraiyah TA et al. A systematic review for the screening for peripheral arterial disease in asymptomatic patients. J Vasc
Surg 2015; 61: 42S-53S. doi:S0741-5214(14)02283-6 [pii] 10.1016/j. jvs.2014.12.008

[11] Parmenter B], Dieberg G, Smart NA. Exercise training for management of peripheral arterial disease: a systematic review and meta-analysis. Sports Med 2015; 45: 231 -244. doi:10.1007/s40279-014-0261-z

[12] Jaff MR, White C], Hiatt WR et al. An Update on Methods for Revascularization and Expansion of the TASC Lesion Classification to Include Belowthe-Knee Arteries: A Supplement to the Inter-Society Consensus for the Management of Peripheral Arterial Disease (TASC II): The TASC Steering Comittee. Ann Vasc Dis 2015; 8: 343 - 357. doi:10.3400/avd.tasc.1501000 avd.tasc. $15-01000$ [pii]

[13] Gerhard-Herman MD, Gornik HL, Barrett C et al. 2016 AHA/ACC Guideline on the Management of Patients With Lower Extremity Peripheral Artery Disease: A Report of the American College of Cardiology/American Heart Association Task Force on Clinical Practice Guidelines. Circulation 2017; 135: e726-e779. doi:CIR.0000000000000471 [pii] $10.1161 /$ CIR.0000000000000471

[14] Landgraf R. National practice guideline therapy of type 2 diabetes. MMW Fortschr Med 2014; 156 Spec No 1: 76-78

[15] Mills JL Sr, Conte MS, Armstrong DG et al. The Society for Vascular Surgery Lower Extremity Threatened Limb Classification System: risk stratification based on wound, ischemia, and foot infection (WIfI). J Vasc Surg 2014; 59: 220-234 e221-e222. doi:S0741-5214(13)01515-2 [pii] 10.1016/j.jvs.2013.08.003

[16] Manzi M, Palena L, Cester G. Endovascular techniques for limb salvage in diabetics with crural and pedal disease. J Cardiovasc Surg (Torino) 2011; 52: 485 - 492. doi:R37116843 [pii]

[17] Adam DJ, Beard JD, Cleveland T et al. Bypass versus angioplasty in severe ischaemia of the leg (BASIL): multicentre, randomised controlled trial. Lancet 2005; 366: 1925 - 1934. doi:S0140-6736(05)67704-5 [pii] 10.1016/S0140-6736(05)67704-5

[18] Leng GC, Fowler B, Ernst E. Exercise for intermittent claudication. Cochrane Database Syst Rev 2000; CD000990. doi:CD000990 [pii] 10.1002/14651858.CD000990

[19] Greenhalgh RM, Belch J], Brown LC et al. The adjuvant benefit of angioplasty in patients with mild to moderate intermittent claudication (MIMIC) managed by supervised exercise, smoking cessation advice and best medical therapy: results from two randomised trials for stenotic femoropopliteal and aortoiliac arterial disease. Eur J Vasc Endovasc Surg 2008; 36: 680 -688. doi:S1078-5884(08)00544-3 [pii] 10.1016/j. ejvs.2008.10.007

[20] Momsen AH, Jensen MB, Norager CB et al. Drug therapy for improving walking distance in intermittent claudication: a systematic review and meta-analysis of robust randomised controlled studies. Eur J Vasc Endovasc Surg 2009; 38: 463 - 474. doi:S1078-5884(09)00298-6 [pii] 10.1016/j.ejvs.2009.06.002

[21] Indes JE, Pfaff M], Farrokhyar F et al. Clinical outcomes of 5358 patients undergoing direct open bypass or endovascular treatment for aortoiliac occlusive disease: a systematic review and meta-analysis. J Endovasc Ther 2013; 20: 443 - 455. doi:10.1583/13-4242.1

[22] Gerhard-Herman MD, Gornik HL, Barrett C et al. 2016 AHA/ACC Guideline on the Management of Patients with Lower Extremity Peripheral Artery Disease: Executive Summary. Vasc Med 2017; 22: NP1 - NP43. doi:10.1177/1358863X17701592

[23] Grimme FA, Goverde PC, Verbruggen PJ et al. Editor's Choice-First Results of the Covered Endovascular Reconstruction of the Aortic Bifurcation (CERAB) Technique for Aortoiliac Occlusive Disease. Eur J Vasc Endovasc Surg 2015; 50: 638 - 647. doi:S1078-5884(15)00540-7 [pii] 10.1016/j.ejvs.2015.06.112

[24] Krankenberg $\mathrm{H}$, Schluter M, Steinkamp H] et al. Nitinol stent implantation versus percutaneous transluminal angioplasty in superficial femoral artery lesions up to $10 \mathrm{~cm}$ in length: the femoral artery stenting trial (FAST). Circulation 2007; 116: 285-292. doi:CIRCULATIONAHA.107.689141 [pii] 10.1161/CIRCULATIONAHA.107.689141 
[25] Laird JR, Katzen BT, Scheinert D et al. Nitinol stent implantation vs. balloon angioplasty for lesions in the superficial femoral and proximal popliteal arteries of patients with claudication: three-year follow-up from the RESILIENT randomized trial. J Endovasc Ther 2012; 19: 1 -9. doi:10.1583/11-3627.1

[26] Cassese S, Byrne RA, Ott I et al. Paclitaxel-coated versus uncoated balloon angioplasty reduces target lesion revascularization in patients with femoropopliteal arterial disease: a meta-analysis of randomized trials. Circ Cardiovasc Interv 2012; 5: 582 - 589. doi:CIRCINTERVENTIONS.112.969972 [pii] 10.1161/CIRCINTERVENTIONS.112.969972

[27] Dake MD, Ansel GM, Jaff MR et al. Durable Clinical Effectiveness With Paclitaxel-Eluting Stents in the Femoropopliteal Artery: 5-Year Results of the Zilver PTX Randomized Trial. Circulation 2016; 133: 1472 - 1483; discussion 1483. doi:CIRCULATIONAHA.115.016900 [pii] 10.1161/CIRCULATIONAHA. 115.016900

[28] De Cock E, Sapoval M, Julia P et al. A budget impact model for paclitaxeleluting stent in femoropopliteal disease in France. Cardiovasc Intervent Radiol 2013; 36: 362 - 370. doi:10.1007/s00270-012-0494-x

[29] Katsanos K, Geisler BP, Garner AM et al. Economic analysis of endovascular drug-eluting treatments for femoropopliteal artery disease in the UK. BMJ Open 2016; 6: e011245. doi:bmjopen-2016-011245 [pii] 10.1136/bmjopen-2016-011245

[30] Zeller T, Langhoff R, Rocha-Singh KJ et al. Directional Atherectomy Followed by a Paclitaxel-Coated Balloon to Inhibit Restenosis and Maintain Vessel Patency: Twelve-Month Results of the DEFINITIVE AR Study. Circ Cardiovasc Interv 2017; 10: e004848. doi:CIRCINTERVENTIONS.116.004848 [pii] 10.1161/CIRCINTERVENTIONS.116.004848

[31] Baumhakel M, Chkhetia S, Kindermann M. Treatment of femoro-popliteal lesions with scoring and drug-coated balloon angioplasty: 12month results of the DCB-Trak registry. Diagn Interv Radiol 2018; 24 : 153 - 157. doi:10.5152/dir.2018.17466

[32] Dominguez A 3rd, Bahadorani ] et al. Endovascular therapy for critical limb ischemia. Expert Rev Cardiovasc Ther 2015; 13: 429-444. doi:10.1586/14779072.2015.1019472

[33] Norgren L, Hiatt WR, Dormandy JA et al. Inter-society consensus for the management of peripheral arterial disease. Int Angiol 2007; 26: 81 - 157

[34] Reinecke H, Unrath M, Freisinger E et al. Peripheral arterial disease and critical limb ischaemia: still poor outcomes and lack of guideline adherence. Eur Heart ] 2015; 36: 932 - 938. doi:ehv006 [pii] 10.1093/eurheartj/ehv006

[35] Jongkind V, Akkersdijk G], Yeung KK et al. A systematic review of endovascular treatment of extensive aortoiliac occlusive disease. J Vasc Surg 2010; 52: 1376 - 1383. doi:S0741-5214(10)01127-4 [pii] 10.1016/j. jvs.2010.04.080

[36] Ye W, Liu CW, Ricco JB et al. Early and late outcomes of percutaneous treatment of TransAtlantic Inter-Society Consensus class C and D aortoiliac lesions. J Vasc Surg 2011; 53: 1728-1737. doi:S07415214(11)00298-9 [pii] 10.1016/j.jvs.2011.02.005

[37] Suzuki K, Mizutani Y, Soga Y et al. Efficacy and Safety of Endovascular Therapy for Aortoiliac TASC D Lesions. Angiology 2017; 68: 67-73. doi:0003319716638005 [pii] 10.1177/0003319716638005
[38] Bosiers M, Deloose K, Callaert ] et al. BRAVISSIMO: 12-month results from a large scale prospective trial. J Cardiovasc Surg (Torino) 2013; 54 : 235 - 253. doi:R37137462 [pii]

[39] lida O, Soga Y, Takahara M et al. Efficacy of the S.M.A.R.T. Control vs. other stents for aortoiliac occlusive disease in contemporary clinical practice. J Endovasc Ther 2013; 20: 431 -439. doi:10.1583/124156MR.1

[40] Tewksbury R, Taumoepeau L, Cartmill A et al. Outcomes of covered expandable stents for the treatment of TASC D aorto-iliac occlusive lesions. Vascular 2015; 23: 630 - 636. doi:1708538114568479 [pii] $10.1177 / 1708538114568479$

[41] Bradbury AW, Adam DJ, Bell J et al. Bypass versus Angioplasty in Severe Ischaemia of the Leg (BASIL) trial: An intention-to-treat analysis of amputation-free and overall survival in patients randomized to a bypass surgery-first or a balloon angioplasty-first revascularization strategy. J Vasc Surg 2010; 51: 5S-17S. doi:S0741-5214(10)00233-8 [pii] 10.1016/j.jvs.2010.01.073

[42] Zhang L, Bao J, Zhao Z et al. Effectiveness of Viabahn in the Treatment of Superficial Femoral Artery Occlusive Disease: A Systematic Review and Meta-analysis. J Endovasc Ther 2015; 22: 495 - 505. doi:1526602815588274 [pii] 10.1177/1526602815588274

[43] McQuade K, Gable D, Pearl G et al. Four-year randomized prospective comparison of percutaneous ePTFE/nitinol self-expanding stent graft versus prosthetic femoral-popliteal bypass in the treatment of superficial femoral artery occlusive disease. J Vasc Surg 2010; 52: 584 - 590; discussion 590-581, 591 e581-591 e587. doi:S0741-5214(10)00904-3 [pii] 10.1016/j.jvs.2010.03.071

[44] Bosiers M, Peeters P, Tessarek J et al. The Zilver(R) PTX(R) Single Arm Study: 12-month results from the TASC C/D lesion subgroup. J Cardiovasc Surg (Torino) 2013; 54: 115 - 122. doi:R37137272 [pii]

[45] Treitl M, Reiser MF, Treitl KM. Stent-assisted recanalization of femoropopliteal arterial occlusive disease. Influence of stent design on patency rates. Radiologe 2016; 56: 233 - 239. doi:10.1007/s00117-016-007710.1007/s00117-016-0077-y [pii]

[46] Zeller T, Baumgartner I, Scheinert D et al. Drug-eluting balloon versus standard balloon angioplasty for infrapopliteal arterial revascularization in critical limb ischemia: 12-month results from the IN.PACT DEEP randomized trial. J Am Coll Cardiol 2014; 64: 1568 - 1576. doi:S07351097(14)05714-3 [pii] 10.1016/j.jacc.2014.06.1198

[47] Enezate TH, Omran J, Mahmud E et al. Endovascular versus surgical treatment for acute limb ischemia: a systematic review and meta-analysis of clinical trials. Cardiovasc Diagn Ther 2017; 7: 264-271. doi:10.21037/cdt.2017.03.03 cdt-07-03-264 [pii]

[48] Karnabatidis D, Spiliopoulos S, Tsetis D et al. Quality improvement guidelines for percutaneous catheter-directed intra-arterial thrombolysis and mechanical thrombectomy for acute lower-limb ischemia. Cardiovasc Intervent Radiol 2011; 34: 1123-1136. doi:10.1007/s00270011-0258-z 